DOI 10.37882/2223-2966.2020.10.18

\title{
ОБСТРУКТИВНЫЙ СИНДРОМ У ПАЦИЕНТОВ ХОБЛ И ХРОНИЧЕСКИМИ И ДЕСТРУКТИВНЫМИ ФОРМАМИ ТУБЕРКУЛЕЗА
}

\section{OBSTRUCTIVE SYNDROME IN PATIENTS WITH COPD AND CHRONIC AND DESTRUCTIVE FORMS OF TUBERCULOSIS \\ V. Lavrenyuk M. Luneva}

Summary: The purpose of this article is to analyze studies on the development and course of obstructive syndrome in patients with COPD and chronic and destructive forms of tuberculosis. The work was carried out on the basis of an antitubercular dispensary. The study involved 230 patients. This is 140 men (57\%) and 90 women (43\%). The average age of patients was $42.3 \pm 1.1$ years. The studied patients ( 230 people) were divided into 2 groups: patients with COPD (74 people) and patients without this pathology (156 people). All patients ' medical histories were studied, anamnesis was carefully collected, and all clinical and instrumental studies were conducted. As a result of the study, it was found that in all cases of tuberculosis, bronchoobstructive syndrome was detected. The most common form of tuberculosis is infiltrative tuberculosis. It was detected in $65 \%$ of patients with COPD and $85 \%$ of patients without it. Chronic obstructive pulmonary disease often accompanies such a pathological process as pulmonary tuberculosis. One of the main manifestations of these conditions is obstructive syndrome. COPD was detected in more than $30 \%$ of patients with newly diagnosed tuberculosis.

Keywords: obstructive syndrome, tuberculosis, chronic obstructive pulmonary disease, bronchopulmonary pathology, smoking.
Лавренюк Владимир Валерьевич аспирант, ФГБОУ ВО «Тихоокеанский Владивостокский Медицинский Университет» Минздрава Российской Федерации; врач-фттииатр, инфекционист пульмонолог,

КГБУЗ «Хорольская чентральная больница» lavrenyuk_90@bk.ru

Лунева Марина Анатольевна врач-фтизиатр, заведующий легочно-терапевтический отделением, ГБУз «Приморский краевой

противотуберкулезный диспансер»

Аннотация: Целью данной статьи является анализ исследований, посвященных изучению особенностей развития и протекания обструктивного синдрома у пациентов ХОБЛ и хроническими и деструктивными формами туберкулеза. Работа проведена на базе противотуберкулезного диспансера. В исследовании приняло участие 230 пациентов. Это 140 мужчин (57 \%) и 90 женщин (43\%). Средний возраст пациентов составил 42,3 $\pm 1,1$ года. Исследуемые пациенты (230 человек) были разделены на 2 группы - это пациенты с ХОБЛ (74 человека) и пациенты без данной патологии (156 человек). у всех пациентов были изучены истории болезни, тщательно собран анамнез, проведены все клинические и инструментальные исследования. В результате исследования было выявлено, что во всех случаях при туберкулезе был обнаружен бронхообструктивный синдром. Наиболее часто встречаемая форма туберкулеза - это инфильтративный туберкулез. Он был выявлен у 65 \% пациентов с ХОБЛ и у $85 \%$ пациентов без нее. Хроническая обструктивная болезнь легких довольно часто сопровождает такой патологический процесс, как туберкулез легких. Одно из главных проявлений данных состояний - 06структивный синдром. ХОБЛ была выявлена более, чем у 30 \% пациентов с впервые выявленным туберкулезом.

Ключевые слова: обструктивный синдром, туберкулез, хроническая обструктивная болезнь легких, бронхолегочная патология, курение.

чаемости сочетания туберкулеза (ТБ) и хронической обструктивной болезни легких (ХОБЛ). Данное явление можно объяснить общими факторами риска данных патологических состояний. Это негативное влияние курени, низкая сопротивляемость организма, а также пагубное влияние отравляющих веществ, содержащихся в выхлопных газах автомобилей [10]. В результате снижения общей сопротивляемости организма при ХОБЛ, микобактерии туберкулеза значительно активизируются, что приводит к возникновению сочетанного патологического процесса. При этом туберкулез охватывает больший объем тканей легких, соответственно, в результате появляется более выраженный бронхообструктивный синдром [7].

Изучение совместного патогенеза исследуемых забо-

В последнее время отмечена высокая частота встре- 
леваний будет способствовать разработке новой методики ведения пациентов с туберкулезом и ХОБЛ, а также поможет существенно снизить уровень инвалидности и смертности от данных патологических состояний.

Согласно статистическим исследованиям, хроническая обструктивная болезнь легких (ХОБЛ) занимает третье место среди причин мировой смертности населения после сердечных заболеваний и инсульта [3]. ХОБЛ встречается у пациентов в возрасте старше 40 лет со статистикой 10-15\%.

Актуальность хронической бронхолегочной патологии объясняется комплексным протеканием вместе с туберкулезной инфекцией [8]. Специфичность развития туберкулеза заключается в том, что данное заболевание может быть локализовано в различных органах и тканях. Но в большинстве случаев встречается именно в виде легочной форме [12]. Отсутствие терапевтических мероприятий превращает туберкулез в хроническую форму, при этом пятилетняя выживаемость составляет 50 \% [7]. Эффективность лечения зависит от соблюдения строгой последовательности и режимности, однако в большинстве случаев (свыше 60\%) после проведенной терапии и после выздоровления выявляются нарушения легочной функции, в частности, регистрируется бронхиальная обструкция [5].

Соответственно, довольно часто встречается коморбидность патологий, когда у пациента одновременно регистрируется туберкулез и ХОБЛ. Согласно исследованиям Всемирной Организации Здравоохранения, в последнее время наблюдается значительное увеличение числа пациентов с коморбиднымый заболеванием туберкулезом и ХОБЛ [4]. Таким образом, изучение формирования и развития обструктивного синдрома при сочетанном действии на организм туберкулеза и ХОБЛ имеет важное значение для разработки дополнительных профилактических и контрольных стратегий и снижения заболеваемости.

Целью настоящего исследования стало проведение анализа изучения особенностей развития и протекания обструктивного синдрома у пациентов ХОБЛ и хроническими и деструктивными формами туберкулеза.

\section{Материал и методы}

Работа проведена на базе КГБУЗ «Хорольская центральная больница». Изучение особенностей обструктивного синдрома проходило с помощью изучения самочувствия пациентов с диагнозом туберкулез, который был диагностирован впервые. В исследовании приняло участие 230 пациентов. Это 140 мужчин (57\%) и 90 женщин (43\%). Средний возраст пациентов составил 42,3 1,1 года. У всех пациентов были изучены истории болез- ни, тщательно собран анамнез, проведены все клинические и инструментальные исследования. Проводилось исследование функции внешнего дыхания, изучалась жизненная емкость легких. При исследовании 230 пациентов у 74 из них дополнительно был поставлен диагноз хроническая обструктивная болезнь легких. Также было выявлено, что 170 пациентов из 230 человек курили. Согласно существующим рекомендациям, основным методом верификации обструкции и степени тяжести ХОБЛ является спирометрия. Диагноз туберкулеза устанавливался на основании клинических, лабораторных и рентгенологических методов исследования с определением формы, наличия или отсутствия бактериовыделения и распада.

\section{Результаты исследования}

В результате полученных данных можно сделать вывод, что курение может выступать как основной провоцирующий фактор развития ХОБЛ при туберкулезе. В свою очередь, ХОБЛ, как системный воспалительный патологический процесс, может выступать в качестве провоцирующего фактора в развитии туберкулезной инфекции. Установлено, что у пациентов с ХОБЛ чаще встречаются распространенные формы с деструкцией и бактериовыделением, при низкой эффективности противотуберкулезной терапии.

В результате исследования также было установлено, что для пациентов с ХОБЛ характерно развитие среднетяжелых и тяжелых форм. Такие формы нуждаются в медикаментозной коррекции. Можно предположить, что оптимизация подходов к лечению ХОБЛ позволит повысить эффективность лечения туберкулеза и снизить эпидемиологическую опасность у данной категории пациентов.

\section{Обсужкение полученных $\Delta$ әнных}

В результате исследования было выявлено, что во всех случаях при туберкулезе был обнаружен бронхообструктивный синдром. Всего диагностируют три формы обструктивного синдрома [10]:

- паратуберкулезный - предшествующий туберкулезу легких ХОБЛ, диагностируемый в 21 \% случаев;

- метатуберкулезный, развивающийся при длительном хроническом течении туберкулеза органов дыхания в 76 \% случаев;

- посттуберкулезный, возникающий после перенесенного туберкулёза на фоне остаточных посттуберкулезных изменений.

В результате статистических исследований установлено, что очаговый туберкулез сопровождается обструктивным синдромом в половине случаев, при инфильтра- 
тивном туберкулезе данная патология выявляется в 56 \% случаев. Намного чаще обструктивным синдромом сопровождается фиброзно-кавернозный туберкулез (почти 80 \% случаев) и диссеминированный туберкулез - почти в $90 \%$ случаев [5].

Исследуемые пациенты (230 человек) были разделены на 2 группы - это пациенты с ХОБЛ (74 человека) и пациенты без данной патологии (156 человек). В результате проведенного исследования было установлено, что наиболее часто встречаемая форма туберкулеза - это инфильтративный туберкулез. Он был выявлен у $65 \%$ пациентов с ХОБЛ и у $85 \%$ пациентов без нее. Однако пациенты с хронической обструктивной болезнью легких наиболее часто подвержены деструкции (выявлено у 83 \% пациентов). В группе пациентов с ХОБЛ чаще имела место лекарственная устойчивость, что требовало назначения более агрессивной медикаментозной терапии [12].

\section{Зак^ючение}

Таким образом, хроническая обструктивная болезнь легких довольно часто сопровождает такой патологический процесс, как туберкулез легких. Одно из главных проявлений данных состояний - обструктивный синдром. ХОБЛ была выявлена более, чем у 30 \% пациентов с впервые выявленным туберкулезом. Большая частота встречаемости деструктивных форм и бактериовыделения, худшие результаты лечения дают право предположить, что ХОБЛ может служить как фоном для присоединения и активного развития туберкулезной инфекции, так и предиктором неблагоприятного течения и исхода заболевания. Внедрение стандартизованной терапии ХОБЛ в схемы лечения пациентов с сочетанной патологией, возможно, будет способствовать повышению эффективности лечения.

\section{ЛИТЕРАТУРА}

1. Авдеев С.Н. Профилактика обострений хронической обструктивной болезни легких / С.Н. Авдеев // Пульмонология. - 2016. - № 5. - С.101-108.

2. Великая 0.В., Руснак А.С. Скрининговое исследование функции внешнего дыхания у больных туберкулезом легких // Системный анализ и управление в биомедицинских системах. 2015. № 2, т. 11. С. 455-458.

3. Визель А.А., Визель И.Ю. Хроническая обструктивная болезнь легких: состояние проблемы 2016 // Лечащий врач. 2016;(4):78.

4. К Клинико-эпидемиологические особенности туберкулеза верхних и нижних дыхательных путей у больных с хроническими неспецифическими заболеваниями легких / А.В. Мордык, Н.В. Багишева, 0.Г. Иванова [и др.] // Folia Otorhinolaryngologiae et Pathologiae Respiratoriae. - 2016. - Т. 22, № 1. - C.84- 90.

5. Кравец С. Л., Ханин А. Л. Бронхообструктивный синдром ХОБЛ у впервые выявленных больных туберкулезом легких. Медицина XXI века: сб. материалов VII научно-практической конференции молодых ученых. Красноярск, 2017:62-65.

6. Лушникова А.В., Великая 0.В. Туберкулёз лёгких и ХОБЛ // Современные проблемы науки и образования. - 2015. - № 6.

7. Макаров И.А. Особенности динамики профессиональной хронической обструктивной болезни легких у рабочих пылевых профессий / И.А. Макаров, И.А. Потапова, Н.В. Макеева // Пульмонология. - 2017. - № 1. - С.37- 40.

8. Мордык А. В., Иванова О. Г., Багишева Н. В. Туберкулез и ХОБЛ: оптимизация сочетанной терапии. Медицинский альянс. 2015; 1:103-104.

9. Мордык А. В., Пузырева Л. В., Батищева Т. Л. Факторы, определяющие исход впервые выявленного инфильтративного туберкулеза у социально сохранных пациентов. Земский врач. 2015;2(26):31-35.

10. Чучалин А.Г. Национальные клинические рекомендации по диагностике и лечению хронической обструктивной болезни легких: алгоритм принятия клинических решений / А.Г. Чучалин, 3.3. Айсанов, С.Н. Авдеев // Пульмонология. - 2017. - № 1. - С.13-20.

11. Шмелев Е.И., Куклина Г.М. Коррекция бронхообструктивного синдрома у больных туберкулезом легких. Медицинский совет. 2015; 3:20-24.

12. Global, regional, and national deaths, prevalence, disability-adjusted life years, and years lived with disability for chronic obstructive pulmonary disease and asthma, 1990-2015: a systematic analysis for the Global Burden of Disease Study 2015. Lancer. 2017;5(9):691-706.

13. Hsing S.C., Weng S.F., Cheng K.C., Shieh J.M., Chen C.H., Chiang S.R., Wang J.J. Increased risk of pulmonary tuberculosis in patients with previous non-tuberculous mycobacterial disease // I nt J Tuberc Lung Dis. 2015. № 17 (7). P. 928-933.

14. De Mello K.G., Mello F.C., Borga L., Rolla V., Duarte R.S., Sampaio E.P., Holland S.M., Prevots D.R., Dalcolmo M.P. Clinical and therapeutic features of pulmonary nontuberculous mycobacterial disease, Brazil, 1993-2011 // Emerg Infect Dis. 2017. № 19 (3). P. 393-399.

15. Taylor A.E., Finney-Hayward T.K., Quint J.K., Thomas C.M. Defective macrophage phagocytosis of bacteria in COPD. Eur. Respir. J. 2018;35:1039-1047.

(с) Лавренюк Владимир Валерьевич (lavrenyuk_90@bk.ru), Лунева Марина Анатольевна. Журнал «Современная наука: актуальные проблемы теории и практики» 